\title{
A Semi-Attending Robotics Couse Proposal: An On-Line Platform and Set of In-Person Meetings For Teaching Robotics Using Lego Mindstorms EV3
}

\author{
Alane Teixeira Rodrigues* \\ *Departamento de Engenharia, Universidade Federal do Ceará, Sobral, Brasil. \\ E-mail: alane.teixeira.r@gmail.com \\ Robson Lopes de Couto \\ •Departamento de Engenharia, Universidade Federal do Ceará, Sobral, Brasil. \\ E-mail: robsonconto@outlook.com \\ Vandilberto Pereira Pinto` \\ ${ }^{`}$ Departamento de Engenharia, Universidade Federal do Ceará, Sobral, Brasil. \\ E-mail: vandilberto@yahoo.com.br \\ Jermana L. de Moraes" \\ 'Departamento de Engenharia, Universidade Federal do Ceará, Sobral, Brasil. \\ E-mail: jermanalopes@gmail.com \\ Rômulo Nunes e C. Almeida ${ }^{\circ}$ \\ ${ }^{\circ}$ Departamento de Engenharia, Universidade Federal do Ceará, Sobral, Brasil. \\ E-mail: rnunes@ufc.com.br
}




\begin{abstract}
The application of robotics as an instrument for boosting the learning process inside classrooms is nowadays a quite reachable reality. The participatory method, in which students and tutors cooperate among themselves for pursuing knowledge, reveals itself as an increasingly easer and didactic manner of passing on knowledge in class. Making use of this learning method, and the interest of the youth for the technological field, a semi-attending robotics course has been delivered by students of the Universidade Federal do Ceará (UFC) to students and teachers from the public schools' system in the municipality of Sobral, State of Ceará, in partnership with the Instituto Virtual of UFC and the Secretaria de Educação de Sobral (SEDUC). It is common that students of secondary education lose interest and feel discouraged when studying some school subjects, because of their abstract nature. Aiming for aiding the teaching of these subjects, such as Mathematics, Physics and Computer Programming, Educational Robotics was used as an effort for making such subjects more interesting and easier to grasp, dynamizing their studying. This project aimed to introduce basic notions about robotics making use of the Lego Mindstorms EV3 kit, with aid of SOLAR, an online platform where the e-learning classes were taught, and the utilization of a visual language for programming the robots, part of the software bundled with the Lego Mindstorms Ev3 kit. The in-person meetings were carried out every last weekend of each month, so that the students could practice programming the Lego Mindstorms and put into use what they had learned in the virtual classes beforehand. At the end of the course, when all the students already had the skills for programming the robotics kit, a competition was held with the intent of harvesting the results obtained over the duration of the course. The teams with best performance were awarded medals and trophies, as recognition of the effort they put in. The participants were also encouraged to keep studying and improving their knowledge of robotics after the end of the course.
\end{abstract}

Keywords: E-Learning, Logic, Programming, Robotics, Teaching.

\title{
1. Introduction
}

Technological diffusion is becoming increasingly rapid and accessible to everyone. New tools have been created every moment to streamline tasks and help life become more practical. With that in mind, it is of extreme importance to insert individuals in the technological context, so that they have the opportunity of using tools which contribute to their intellectual or even professional development, such as educational robotics.

Educational Robotics turn ups as a highly effective tool, not only in the technological learning context, but also in the improvement of teamwork, logical thinking, problem solving and creativity stimuli. The interest for the new is indicated instinctively when students discover they can program a robot with the Lego Mindstorms EV3 kit and use it in the most varied means.

The Lego Mindstorms EV3 kit has a playful programming interface, which eases the schooling of robotics to people who never thought they would be able to build and program their own robot. The programming language of the Mindstorms software is visual, composed of blocks, dynamizing the learning process. An entertaining schooling software is extremely important so that the students do not feel overwhelmed when coming across the possible difficulties of a more complex text-based programming language, such as $\mathrm{C} / \mathrm{C}++$. This way the students are more motivated and expected to stay in the course until its end.

The present work aims to address robotics as a learning artifice in the public schools of the countryside of Ceará, closely with aid of a visual programming software environment and an online learning platform, SOLAR, which allows quick and easy communication between 
students and teachers.

This work is structured as following: in section 2 is explained the reasons for using robotics as a schooling tool. Section 3 address the Lego Mindstorms robotics kit, including its software. In section 4 , it is explained the structure of our course, including the e-learning and in person classes. To finalize, section 5 presents the conclusions about the implementation of the course.

\section{Robotics as A Schooling Tool}

Robotics is defined as the science which studies building and programming of robots. A robot, being an equipment which, in a planned manner, requires the connection of varied components, demands knowledge of many fields. Thus, robotics is a resource for promotion of interdisciplinarity ${ }^{1}$.

The main objective of educational robotics is to promote meaningful learning, which is process by a new information (a new knowledge) relates in a non-arbitrary and substantive (non-literal) to the cognitive structure of the apprentice. In the course of the meaningful learning that the logical understanding studying material transforms into a psychological meaning to the individual ${ }^{2}$.

Therefore, robotics can be utilized within the school ambient as a methodology to encourage the students to analyse and put into use concepts acquired as curricular content. Furthermore, it can develop in students other skills, such as the teamwork spirit, problem solving ability, expose their thoughts and seek solutions which involve concepts from other subject areas, as Physics, Mathematics, Science, among others.

The robotics is a field that covers several subjects and can be used in teaching various areas, other skills being necessary for robot creation $^{3}$.

The main stimuli developed by this pedagogical practice are ${ }^{4}$ :

1. Development of reasoning and logic in the building of prototypes that simulate reality;

2. Development of aspects linked to planning and organization of projects;

3. Analysis ability in the study of gears and complex systems in order to understand their operation;

4. Creativity in the production of robots; Problem solving ability;

5. Autonomy; and

6. Cooperation.

\section{The Lego Mindstorms EV3 Kit}

This kit is used predominantly in institutional context, as it is composed of pluggable parts, motors and sensors, which facilitate the building of diverse sorts of robots without any extra tools. A programmable brick is also included, where the programmed algorithms are stored and executed. This brick is programmed through a software which makes use of a visual programming language, more intuitive and simpler to beginner students. In the Figures 1, 2 and 3, it is possible to visualize all the parts that compose the Lego Mindstorms EV3 kit, some possible builds and the programmable brick, respectively. 


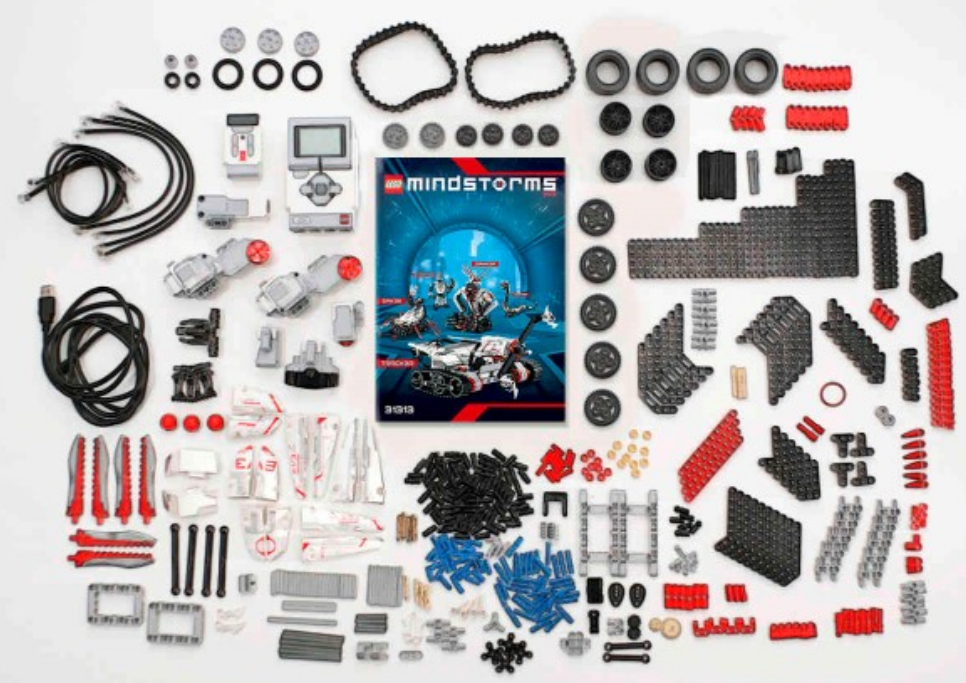

Figure 1. Lego Mindstorms EV3 parts.

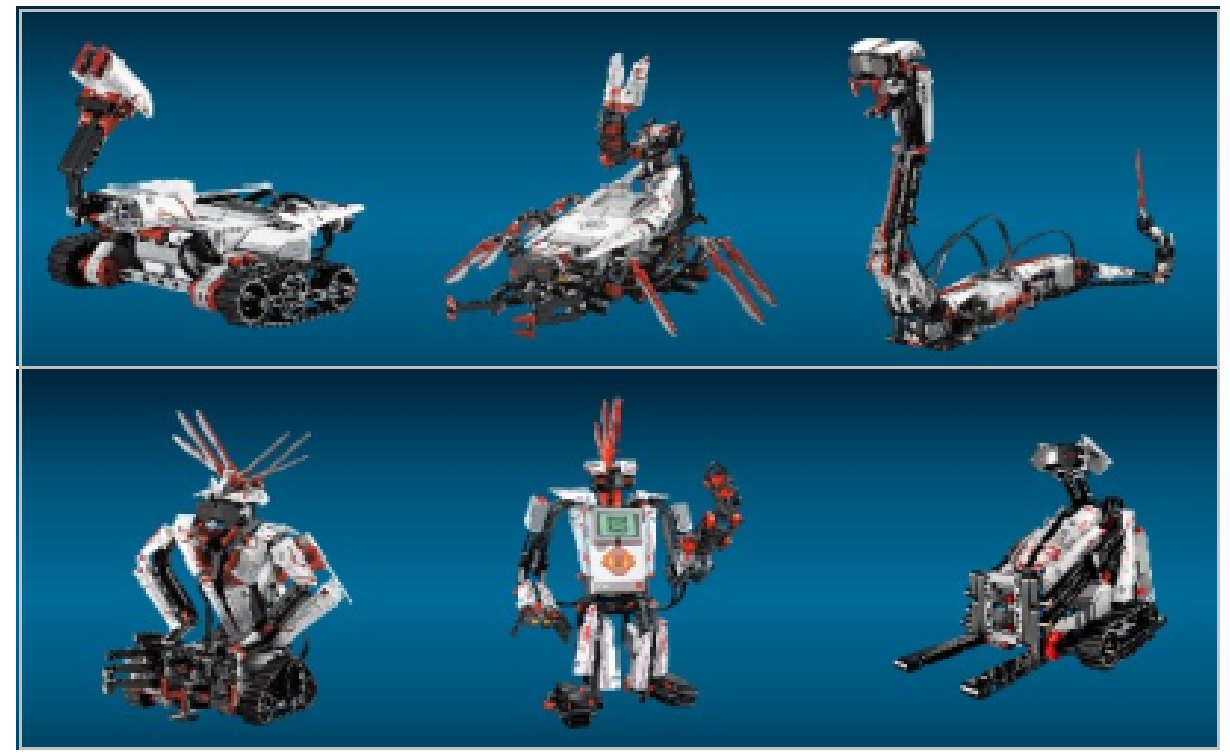

Figure 2. Possible robot builds. 


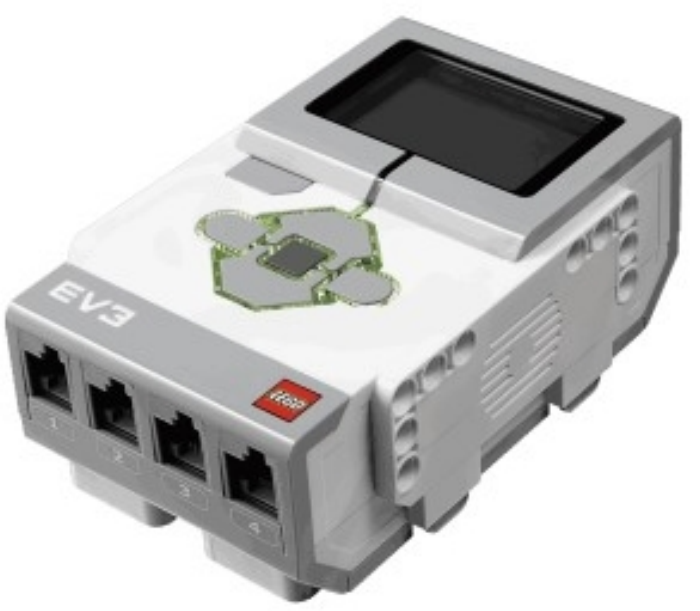

Figure 3. Programmable Brick.

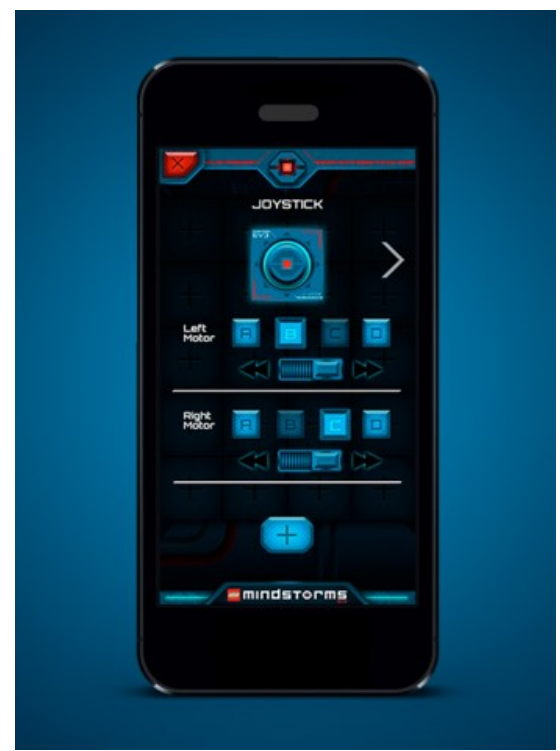

Figure 4. Lego Robot Commander App.

Combining the pluggable parts with the brick, motors and sensors, one can build robots which are capable of walking, picking up or shooting plastic balls, play sounds, among other functions.

There are two ways of controlling the robots: The Ciclo Camp Project arose from the need to broaden the range of means of transportation in the Campus do Vale, and it boasts the following qualities:

- For instantaneous control: one can use the remote controller or the official Lego Mindstorms smartphone application, shown in the Figure 4, which is freely available and can be installed in most smartphones. The wireless communication between the application and the brick is carried over Bluetooth, dismissing the need of a computer to control the device; and

- For automatic actions, it is possible to create your own algorithm using the Lego 
Mindstorms software, available on the official Lego website. This software can be installed in tablets and computers.

The software for the Lego Mindstorms EV3 kit is available for Windows and Mac OS Computers ${ }^{5}$. The brick can also be programmed from a tablet, or its own user interface, that is, its own display and buttons, however this interface is quite limited. The layout of the computer software can be seen in Figure 5.

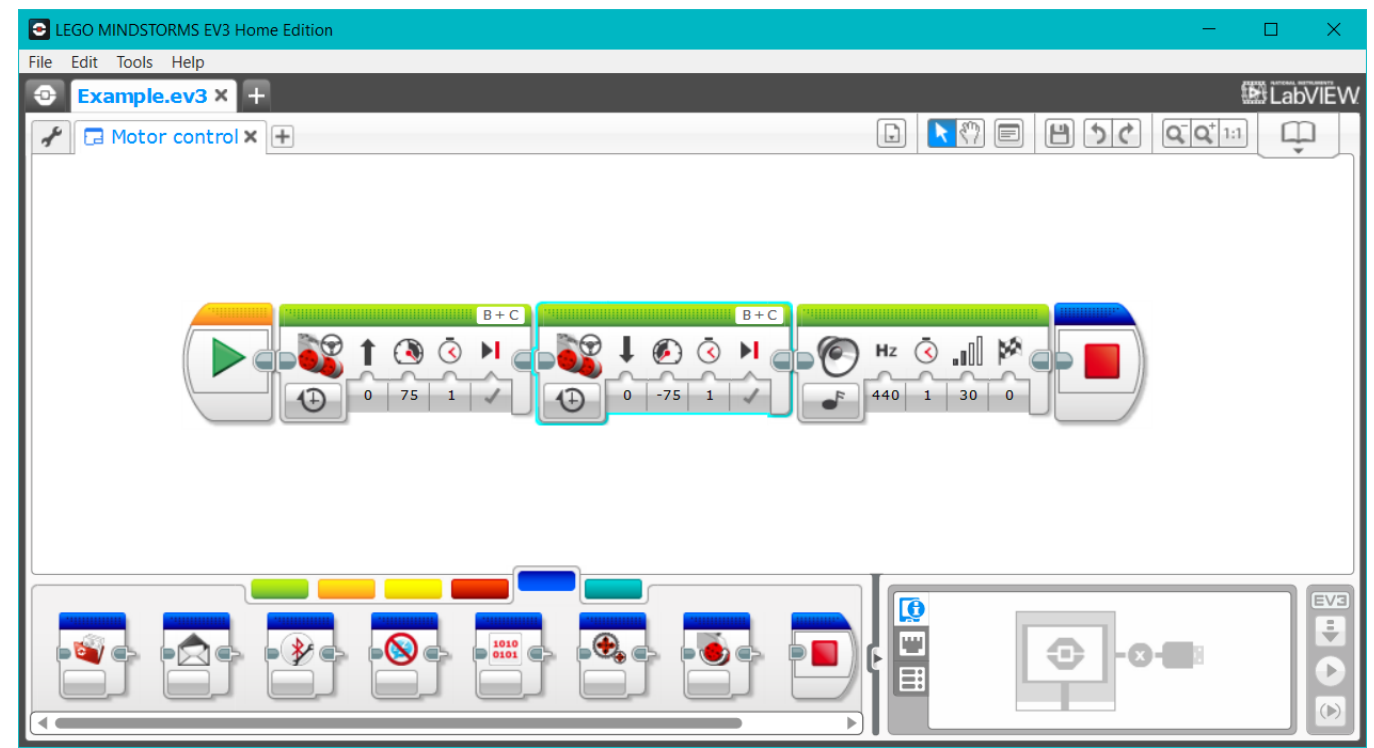

Figure 5. Software Lego Mindstorms EV3 for Windows.

The robot programming is carried through connecting diverse blocks on the software. These blocks have an intuitive interface and are quite easy to understand, differently from the most kind of programming languages which are based on code, using functions and commands. These blocks are combined to shape the algorithm that will dictate the behaviour of the programmed robot. Visual based languages offer an easier manner to students of comprehending the algorithm they wish to program the robot with, which would be considerably more difficult using code.

The programming blocks are separated by functionality and each kind uses a specific, these being:

- Action blocks, symbolized by the color green: these allow to spin the motors, write text or show images on the display and play sounds on the speaker;

- Flow blocks, symbolized by the color orange: these are equivalent to loop structures, as while; or conditional structures, such as if; present in regular computer programming languages;

- Sensor blocks: allow reading values of sensors present in the kit, such as the infrared sensor, touch sensor, color sensor and the buttons present on the brick. These are represented in yellow;

- Data operation blocks: these are red and enable the use of variables, arrays and some Logical and Mathematical operations;

- Advanced blocks, of blue color: are used to access files, Bluetooth communication, messages and other operations; and

- The blocks in turquoise are similar to functions, that is, can be created to substitute a whole set of blocks for only one, which can then be reused whenever necessary. 
The blocks have parameters which can be easily edited, for example, the time in seconds for how long a motor must be activated. The types of blocks listed before are shown in the Figure 6 .

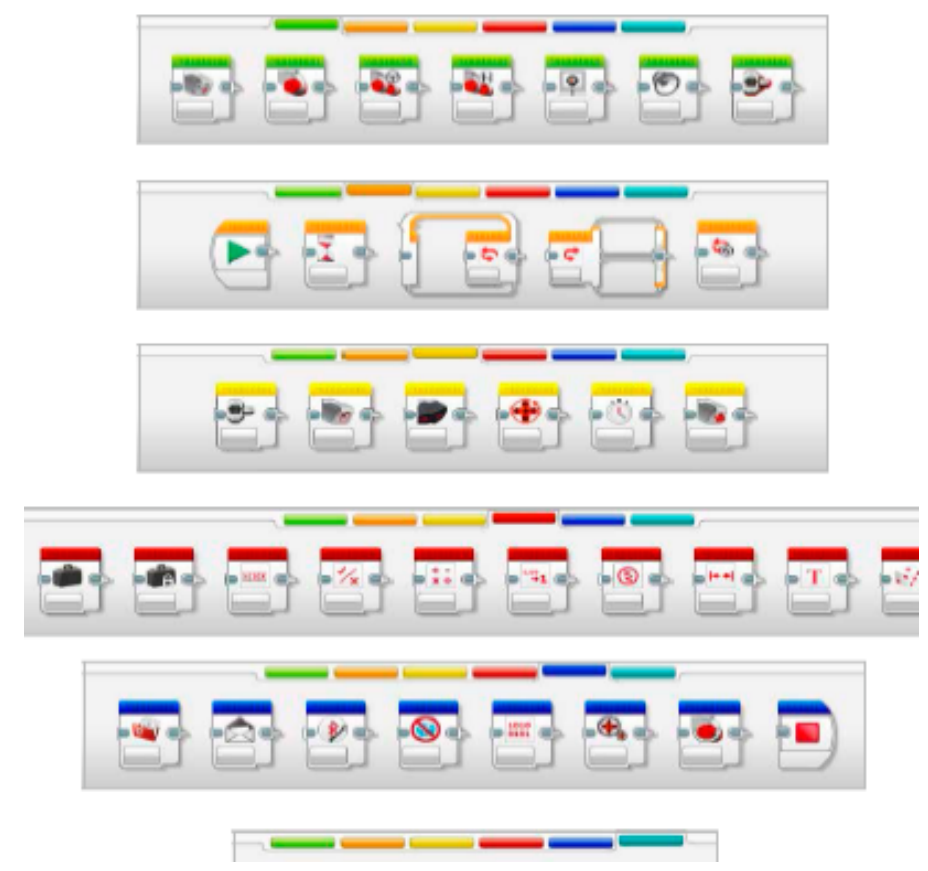

Figure 6. Blocks for programming the kit Lego Mindstorms EV3.

\section{Classes Methodology}

The classes were delivered in two environments: a virtual one, and an attending one. In the virtual classes, the students were instructed through forums, videos, texts and presentations, among other activities. In the meetings, the students had the opportunity to program the Lego Mindstorms EV3 and put into practice what they learned previously on the online platform.

The virtual classes happened during the first three weeks of each month and the meetings every last week, normally on weekends, with duration of four hours. The course was carried over the months of August to November of 2017, summing a course load of 120 hours.

With the intention of measuring the performance of the students and their learning over the duration of the course, a competition was organized, where the students had to solve problems in a pre-established time limit.

\subsection{E-Learning Classes}

The e-learning classes were delivered through an online platform, SOLAR, shown in the Figure 7, which is a website from the Universidade Federal do Ceará focused in distance learning. In this platform, it is possible to organize the students into classes, offering a better assistance from this organization. Moreover, also on this website it is possible to make 
available study materials such as handouts, slides, video lessons, as well keep a channel of quick communication between tutors and students.

The online course was structured in the following manner:

1. Posting of weekly study material;

2. Two weekly activities assigned to the students, according to contents of the previously uploaded material; and

3. Forum for clearing doubts with the tutors.

The study material was posted on the beginning of the week, so that the students could study it and work on its activities on the determined deadlines.

The participation of each individual on this stage was indispensable and each activity was counted as participation scores, which were evaluated together with the course load and accounted towards the end of the course, for receiving the course certificate. Solely the students with a minimum of $75 \%$ of all activities, including the in-person meetings could receive a certificate.

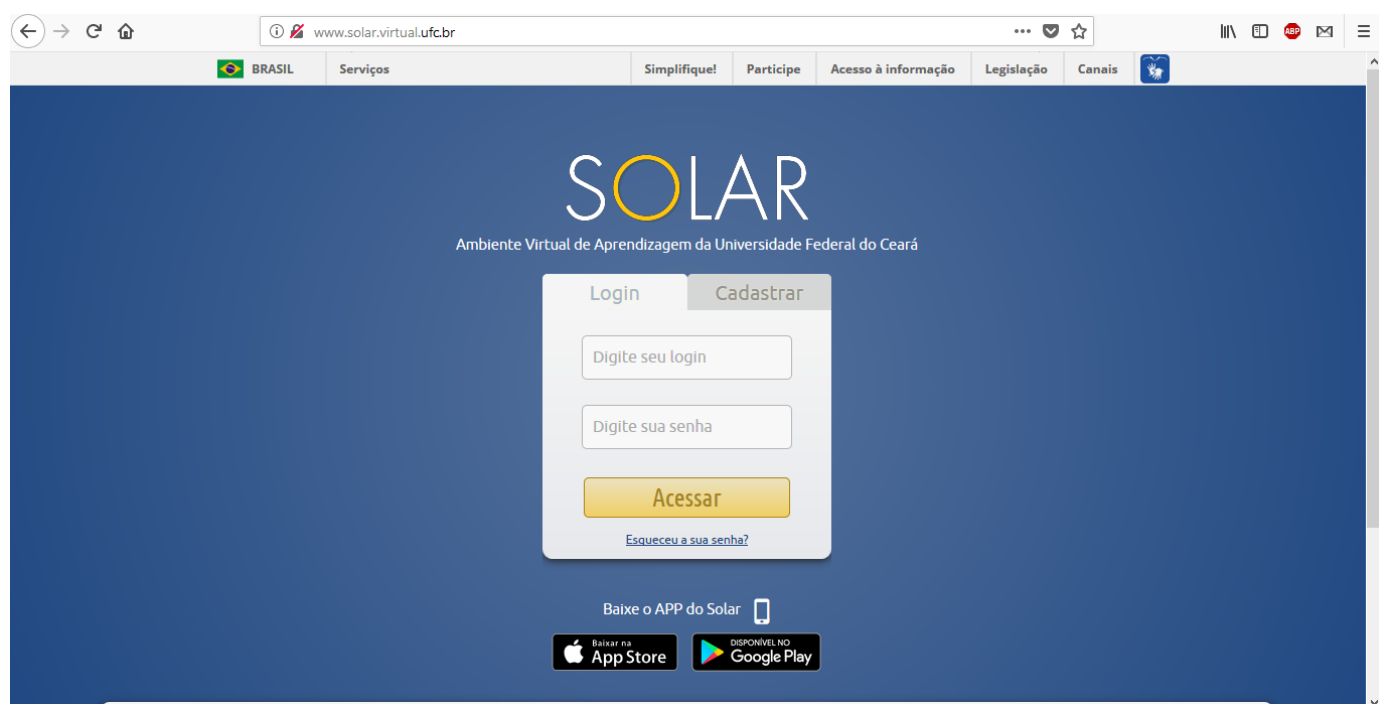

Figure 7. SOLAR platform homepage.

\subsection{Fonts}

The in-person classes provided a better interaction between students and tutors. This is when the students had the opportunity to train what was learned previously on the online platform. In these classes the students made use of the software to program the robots.

In these monthly meetings, the tutors reviewed the content previously addressed on SOLAR, cleared doubts and proposed challenges so that the students would practice programming the Lego Mindstorms EV3. The Figure 8 shows the students practicing with the kit. 


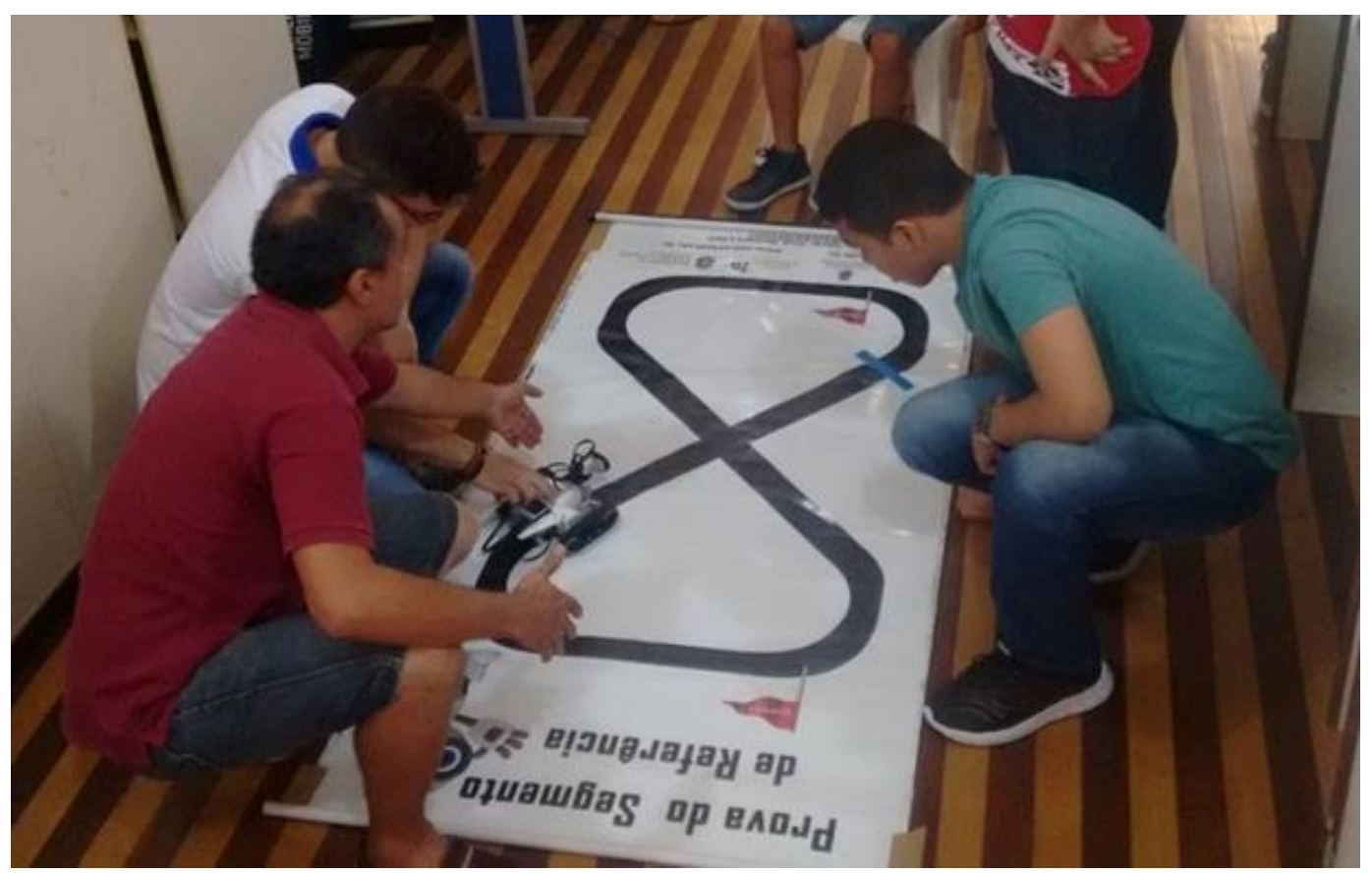

Figure 8. Students practicing with the kit.

Following, it is listed the content of these classes:

- Meeting 1: Introductory class about robotics and the Lego Mindstorms EV3 kit, with the intent of making the students familiarized with the hardware and software. After the introduction to the kit, it was proposed a challenge to students called go ahead. They had to control the motors of the vehicle so that the latter went straight for a determined time;

- Meeting 2: challenge Go and Come Back. The vehicle had to be programmed to move straight ahead to determined place and then turn around and come back to the starting point following the same trajectory. Also, a challenge called Mind the Wall, where the vehicle had to identify an obstacle and avoid it;

- Meeting 3: challenge Reference Follower, in which the vehicle had to follow a path denoted by a marked dark strip on the floor; and

- Meeting 4: Final competition.

\subsection{Competition}

The competition happened on the fourth meeting. In this event, it was possible to obtain the feedback of the work of the tutors by the students, besides providing a moment for teamwork between the participants.

Three equal tasks were designed to all the teams, where the time for solving the task depended on the difficult of the task itself. The first task, for example, had to be solved by all the teams simultaneously before the time limit. Figure 9 shows some participants in the test room, programming their vehicles.

Finished the time for each task, all the teams would was redirected to another room, where the guests invited the competition organization would evaluate the solution of the task according to three criteria: time the vehicle took to complete the path, effectiveness of the algorithm and if the challenge was completed. Each criterion was evaluated from 0 to 
10 and the team which accumulated at the end of the three challenges, was the winner. The Figure 10 shows the challenge evaluation room used by the competition organization.

At the end of the competition, the students received their certificates and the winner teams were contemplated with medals and trophies. The Figure 11 shows the awarding of the winner team.

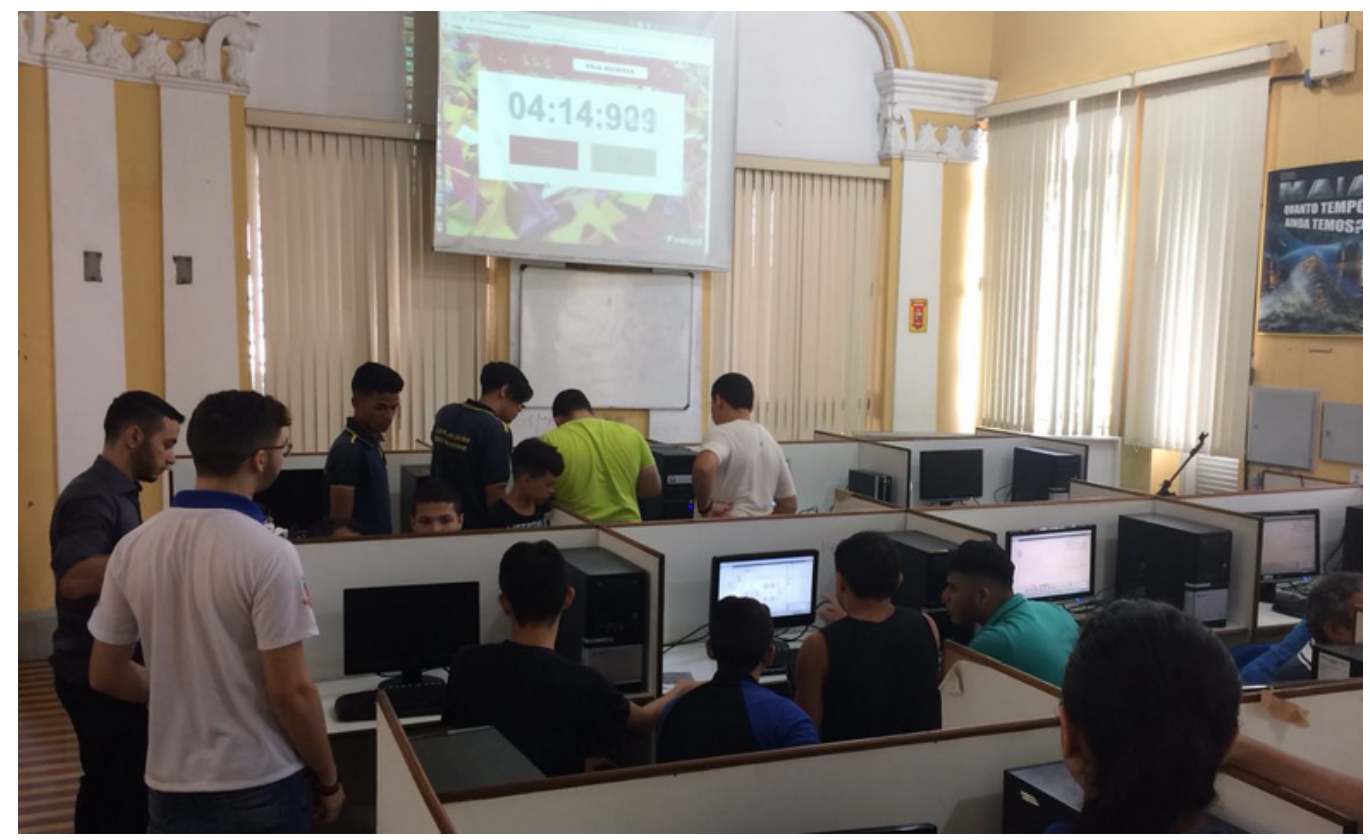

Figure 9. Students programming the robots in the test room.

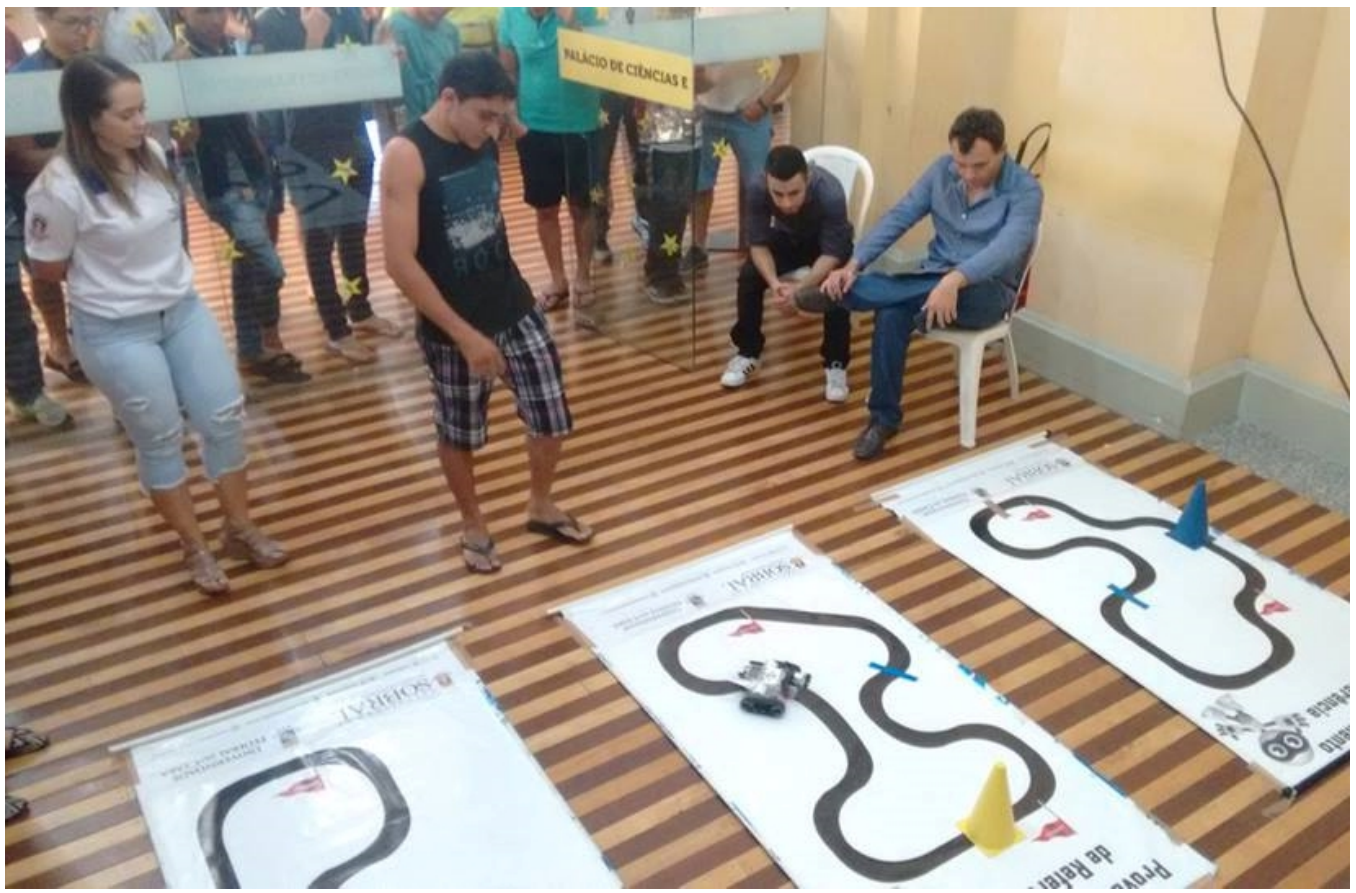

Figure 10. Challenge evaluation room. 


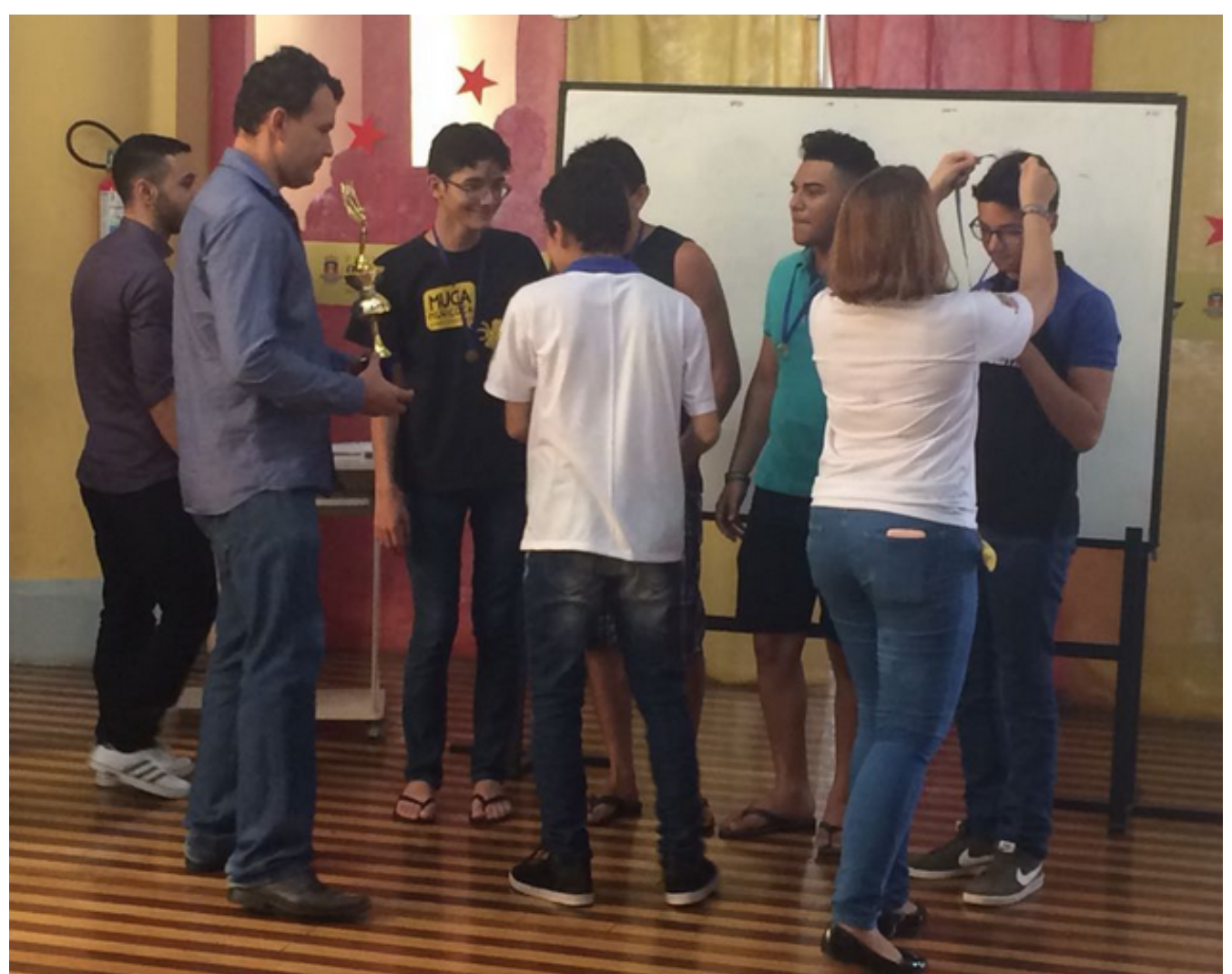

Figure 11. Awarding of the winner team.

\section{Conclusions}

The Educational Robotics course was delivered by scholars of the Universidade Federal do Ceará, campus Sobral, in a project of academic extension. It had the intent of providing students and teachers from the public schools in the municipality of Sobral an initial contact with educational robotics.

We believe the course has fulfilled our objectives. Firstly, bring the students of the local public schools a quality robotics course, awakening on the students the interest for Technology and Exact Sciences in general. These students could realize that with dedication, even children and teenagers can build and program robots.

Secondly, the course has also functioned as a bridge between the University and the local community, namely the local public schools. Through the Educational Robotics Course, students get in touch with the courses of Electrical and Computer Engineering from UFC, this way they may consider in the future enrol in one of these courses.

It was verified that the materials and methods helped secure the success of the course. The Lego Mindstorms EV3 is ideal for children and teenagers, since it is easily built and intuitively programmed. The SOLAR e-learning platform enabled a continuous monitoring of the students learning, through activities, forums and studying materials.

The competition at the end of the course allowed the evaluation of the students' performance. These demonstrated ability for programming the robots, as well quick logical thinking to elaborate good algorithms to accomplish the goals of the challenges. 


\section{Reference}

1. PORTO, M. B. D. Da S. M.; OLIVEIRA, E. R. A imagem no desenvolvimento do projeto de iniciação científica e tecnológica junior em robótica educativa. E-mosaicos, Rio de janeiro, v. 6, n. 12 , p. $1-25,2018$.

2. MOREIRA, M. A.; CABAllero, M. C.; RODRÍGUEZ, M. L. Actas del Encuentro Internacional sobre el Aprendizaje Significativo. Espanha: Burgos, p. 19-44, 1997.

3. NASCIMENTO, P. C. Inteligência Artificial. Available in: $<$ http://www.unicamp.br/unicamp/unicamp_hoje/ju/f ev2002/unihoje_ju170pag04.html $>$. Accessed on: 25 Apr. 2019.

4. Robótica educacional. Available in: $<$ http://www.doaluno.com.br/servicos/projetorobotica/Proj etoRobotica.asp>. Accessed on: 25 Apr. 2019.

5. THE LEGO GROUP - Kit Mindstorms EV3. Available in: $<$ https://www.lego.com/enus/mindstorms/products/ mindstorms-ev3-31313 $>$. Accessed on: 15 Aug. 2018. 